\title{
ANALYSES OF TURBIDITY AND ACOUSTIC BACKSCATTER SIGNAL WITH ARTIFICIAL NEURAL NETWORK FOR ESTIMATION OF SUSPENDED SEDIMENT CONCENTRATION
}

\author{
Meral, R. $^{{ }^{*}}-$ DOGAn DemiR, A. ${ }^{1}-$ CEMEK, B. $^{2}$ \\ ${ }^{1}$ Biosystem Engineering, Bingol University \\ Bingol, Turkey \\ ${ }^{2}$ Department of Agricultural Structures and Irrigation, 19 May University \\ Samsun, Turkey \\ *Corresponding author \\ e-mail: rmeral@bingol.edu.tr; phone: +90-531-790-9280 \\ (Received 23 ${ }^{\text {rd }}$ Aug 2017; accepted 20 $0^{\text {th }}$ Dec 2017)
}

\begin{abstract}
The commonly used sampling method is restrictive for the spatial and temporal measurement of suspended sediment and requires intensive labor. These limitations and technological advances have led to methods based on sound or light scattering in water. In this study, the turbidity and acoustic backscattering signal (ABS) values were used with the aim of improving these methods with different artificial neural network (ANN) models; Multilayer Perceptron (MLP), Radial Basis Neural networks (RBNN) and General Regression Neural Network (GRNN). Measurements were taken in a vertical sediment tower for two different sediment sizes $(<50 \mu \mathrm{m}$ and 50-100 $\mu \mathrm{m})$ and concentrations $(0.0-$ $6.0 \mathrm{~g} \mathrm{~L}^{-1}$ ). In the results of the regression analyses, turbidity values had strong relationships with sediment concentration for both sediment size groups $\left(\mathrm{R}^{2}=0.937\right.$ and 0.967$)$. Although the ABS values had a reasonable $\mathrm{R}^{2}$ value $(0.873)$ for the $50-100 \mu \mathrm{m}$ group, the $<50 \mu \mathrm{m}$ group did not produce a significant $\mathrm{R}^{2}$ value with regression analyses. The remarkable differences were not observed among MLP, RBNN and GRNN model for this sediment size group, and the reasonable $\mathrm{R}^{2}$ and RMSE results were not produced with any ANN model that had a single ABS input for the $<50 \mu \mathrm{m}$ sediment group. On the other hand, for the other sediment group $(50-100 \mu \mathrm{m})$, ABS values were used as a single input, and the highest $\mathrm{R}^{2}$ (0.917) value was obtained with MLP model and it was improved with the turbidity input (up to $\mathrm{R}^{2}=0.999$ ). The results show that the ANN model could be considered as an alternative method because it was applied successfully to estimate suspended sediment concentration using with turbidity and ABS under different particle size conditions.
\end{abstract}

Keywords: environmental, water quality, sediment transport, acoustic algorithm, particle size

\section{Introduction}

Sediment transport in river is the crucial technical problem for many environmental and engineering practices. But its monitoring has many difficulties especially during high discharge and rough water-level conditions. The direct water sampling method is generally used as traditionally. But it is restrictive to represent spatial and temporal analysis of suspended sediment concentration, (Thorne and Hanes, 2002; Guerrero et al., 2016). Because sediment concentration high variable parameter depends on flow, climate and basin conditions (Gray et al., 2002). The size and concentration of sediment are mainly affected by intensity and volume of precipitation, texture and erodibility of soil, topography and land cover properties (Melesse et al., 2011). In addition; time and labor consumed for sampling and filtering processes are the other limitations of this method (Wren et al., 2000; Schoellhamer and Wright, 2003; Tfwala and Wang, 2016). Besides these limitations, continuous and precision sediment-monitoring requirements have led to new devices, especially in terms of using light and sound scattering or 
attenuation by particles in water. This new technique has gained importance within the sedimentological community, and its validation has been tested in many laboratory and field studies (Pedocchi and Garcia, 2012).

Turbidity as a physical value is defined as an optical property that causes light to be scattered and absorbed rather than transmitted in straight lines through the sample (APHA, 2012). Scattering and absorption of light occurs on mineral suspended particles, colloids and bacterioplankton units, air bubbles and other suspended materials in the water sample (Lewis and Eads, 2001). The possibility of simultaneous observations of turbidity and its relationship between suspended sediment concentrations (SSC) has led to the use of turbidimetry to monitor sediment transportation (Uncles and Stephens, 2010). The use of turbidity values for SSC is an indirect method and based on determination of the statistical relationship between these values; the relationship could be linear, non-linear or polynomial (Sun et al., 2001). In addition the Regression equation should be considered individually for each stream condition with variations following the change of hydrological seasons (Williamson and Crawford, 2011). Changes in sediment size, mineral composition and water quality properties are the main limitations of this method. These effects should be considered and defined for different conditions to more accurately estimate sediment concentration with turbidity values (Ziegler, 2002). Tananaev and Debolskiy (2014) reported that the effecting factors of turbidity and sediment grain size should be considered in multivariate models, to minimize errors and acquire an understanding of its response. Mitchell et al. (2003) conducted a turbidity study using river conditions, and they reported that water quality and sediment properties were strongly affected, leading to errors in turbidity measurements, especially in spring season conditions. Chanson et al. (2008) conducted a laboratory study and produced a strong relationship $\left(\mathrm{R}^{2}=0.992\right)$ between sediment concentration and turbidity (Nephelometric Turbidity Units, NTU) at low concentrations $\left(0.8 \mathrm{~g} \mathrm{~L}^{-1}\right)$ for silt and sand sediment materials. Slaets et al. (2014) used the cumulative rainfall values as additional input parameter to estimate sediment concentration with turbidity measurement. Pearson's correlation coefficient was improved with Multiple linear regression analyses up to 0.87 compared with single (turbidity) parameter.

The acoustic sediment measurements, as other new technology, are based on sound waves spreading through the water column. The strength of the sediment particles' backscattered signal is used to estimate the particles' properties. The sediment particle size and concentration in the water can be computed using multi-frequency acoustic backscattering signal (ABS). For this purpose, three or four frequencies in the range $0.5-5 \mathrm{MHz}$ are usually used in transceiver and receiver mode (Thorne and Meral, 2008). Acoustic sediment measurement studies have been applied successfully under different field and laboratory conditions. These studies' results confirmed that particle size and concentration can be estimated relatively non-intrusively and with high spatial and temporal resolution using ABS (Thorne and Hurther, 2014; Ruessink et al., 2011; O'Hara Murray et al., 2012; Aagaard, 2014; Thosteson and Hanes, 1998; Thorne et al., 1998). However ABS is an indirect method and an inversion algorithm is required to convert the backscattered signal to a sediment concentration (Wilson and Hay, 2015; Clay and Medwin, 1997).

The main principle of ABS can be defined using the backscattering and attenuating characteristics of the particles in suspension, which are used for the acoustic inversion algorithm. The backscattering characteristic of the sediment particles is represented with 
the form function, and the attenuation characteristic is represented with the normalized total scattering cross-section. Both are non-dimensional parameters, and their origins are based on the acoustic properties of sphere particles (Neubauer et al., 1974). The sphere scattering properties, using the form function and normalized total scattering cross-section, were first reported by Sheng and Hay (1988). They used a solid sphere model and formulated a simple expression agreed with the data. Many researchers have adopted a similar expression (Thorne and Hurther, 2014; Hay and Sheng, 1992; Crawford and Hay, 1993; Thorne and Hardcastle, 1993; Schaafsma and Hay, 1997; Kisi, 2005). Thorne and Meral (2008) produced an expression for backscattering and attenuating characteristics that compared well with all the data sets available and that could be used with a reasonable degree of confidence to interpret ABS data collected above sandy sediments.

Many researchers have applied the backscattering signal to estimate suspended sediment, but difficulties and complexity remain in the acoustic algorithm. This requirement has led to alternative approaches to formulating the inversion (Thorne and Hurther, 2014). An artificial neural network (ANN) can be used to estimate a suspended sediment concentration based on the measured backscattered signal strength. The ANN technology has provided reasonable results in many complex nonlinear models used in hydrological studies. Kisi (2005) investigated the performance of the neural network method for modeling suspended sediment transportation. Nourani and Kalantari (2010) used rainfall and runoff parameters to determine spatiotemporal modeling of sediment with Artificial Neural Network. Maanen et al. (2010) used an ANN model to predict the suspended sediment with the input variables flow velocity, water depth and wave height, and they reported that using ANN models can improve sediment transport monitoring. Wang et al. (2009) used flow rate and turbidity values as input parameters for an ANN model to estimate sediment concentration, obtaining reasonable results. Similar ANN models studies have been used for many different types of input data, and strong correlations have been obtained for sediment prediction (Abrahart and White, 2001; Nagy et al., 2002; Yitian and Gu, 2003; Cigizoglu, 2004; Alp and Cigizoglu, 2007).

In this study, an acoustic backscattering signal (ABS) and the turbidity method were used for two different sediment-size groups in laboratory conditions. The study aimed to improve both methods by using regression and different ANN models to reduce the complexity of the acoustic algorithm.

\section{Materials and methods}

This study was conducted in a 50-L sediment tower under laboratory conditions. The sediment tower was used to prepare homogenous suspended sediment, which was mixed with a propeller operated by an electric motor. Natural sediment materials were used for both the $0-50 \mu \mathrm{m}$ and $50-100 \mu \mathrm{m}$ groups. Nearly 60 different concentrations were prepared, up to $6.0 \mathrm{~g} \mathrm{~L}^{-1}$ for both sediment-size groups.

An AQUAscat-L (Aquatec Group) device was used with $2 \mathrm{MHz}$ frequency for the acoustic backscattering measurements (Fig. 1). The transducer was fixed vertically at the top of the tower, and backscattered signals were measured at $0.01 \mathrm{~m}$ intervals for each second during a 2-min period for both sediment groups. Turbidity measurements were made simultaneously with ABS using a Seapoint Turbidity Meter (Fig. 1). This device detects light scattered by suspended particles in water and produces an output 
voltage. The output voltage is calibrated to turbidity in formazine turbidity units (FTU). The unique optical design confines the sensing volume to within $5 \mathrm{~cm}$ of the sensor, allowing near-bottom measurements and minimizing errant reflections in restricted spaces (Smerdon, 2006). The measured data were saved by an external data logger. The turbidity sensor read 60 values per minute and a total of 120 turbidity values were taken during a 2-min period for each concentration. In addition, tree water samples $(250 \mathrm{~mL})$ were taken to determine the real sediment concentration with the gravimetric method.

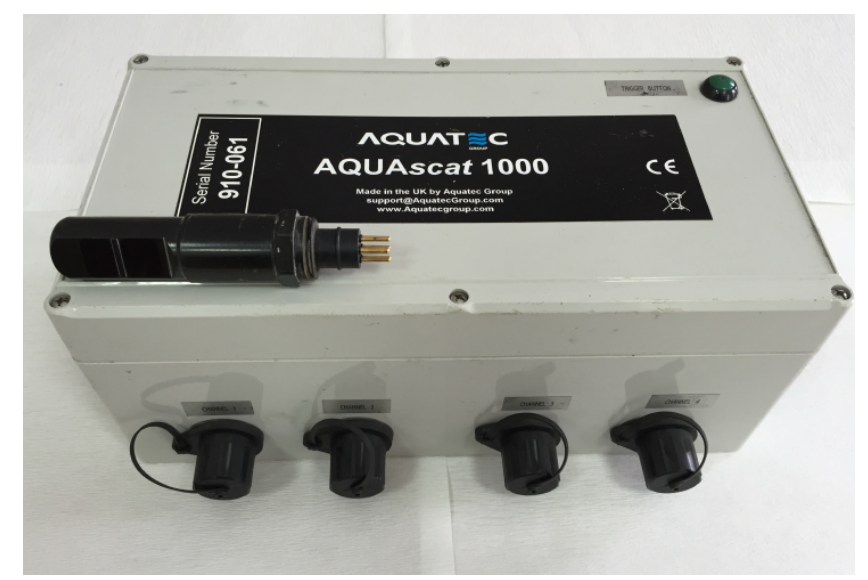

Figure 1. The AQUAscat-L (Aquatec Group) device and Seapoint Turbidity Meter sensor

The regression analyses were applied to obtain the relationship between the sediment concentration with the ABS signal and the turbidity values. These relationships were evaluated using determination coefficient $\left(\mathrm{R}^{2}\right)$, root mean squared error (RMSE) and mean absolute error (MAE). As an alternative method, the ANN method was carried out to estimate sediment concentration using the ABS and turbidity values. In addition, a single input parameter was performed to get a simple alternative for sediment measurement. Different network topologies with single or double hidden layers and varying numbers of neurons were created using the Neural Network Toolbox for MATLAB software. Structures of ANN models are given in Figure 2. The measured data set was used $70 \%$ for training and $30 \%$ for testing, producing an ANN model. Finally, the ANN models were evaluated using $\mathrm{R}^{2}$, RMSE and MAE.

Although there are many alternative models of ANN, in this study the Multilayer Perceptron (MLP), Radial Basis Neural networks (RBNN) and General Regression Neural Network (GRNN) were applied. A feed forward MLP network is formed by simple neurons called perceptron. The perceptron computes a single output from multiple inputs by making a linear combination according to its input weights and then determining the output through a nonlinear transfer function (Singha et al., 2012). The RBNN network is feed-forward network trained using a supervised training algorithm. The RBNN has connection weights between the hidden layer and the output layer only and an activation function is used as radial basis. It does not perform parameter learning as in MLP, performs linear adjustment of the weights fort the radial bases. The RBNN usually train much faster than back propagation networks. They are less susceptible to problems with non-stationary inputs because of the behavior of the radial basis function hidden units. The GRNN is a variation of the RBNN and is based on kernel regression networks. It consists of four layers: input layer, pattern layer, summation layer and 
output layer. The GRNN is based on the non-linear regression model. It estimates most probable output values for given input training set with the minimum mean-squared error (Cigizoglu, 2004; Alp and Cigizoglu, 2007).

a)
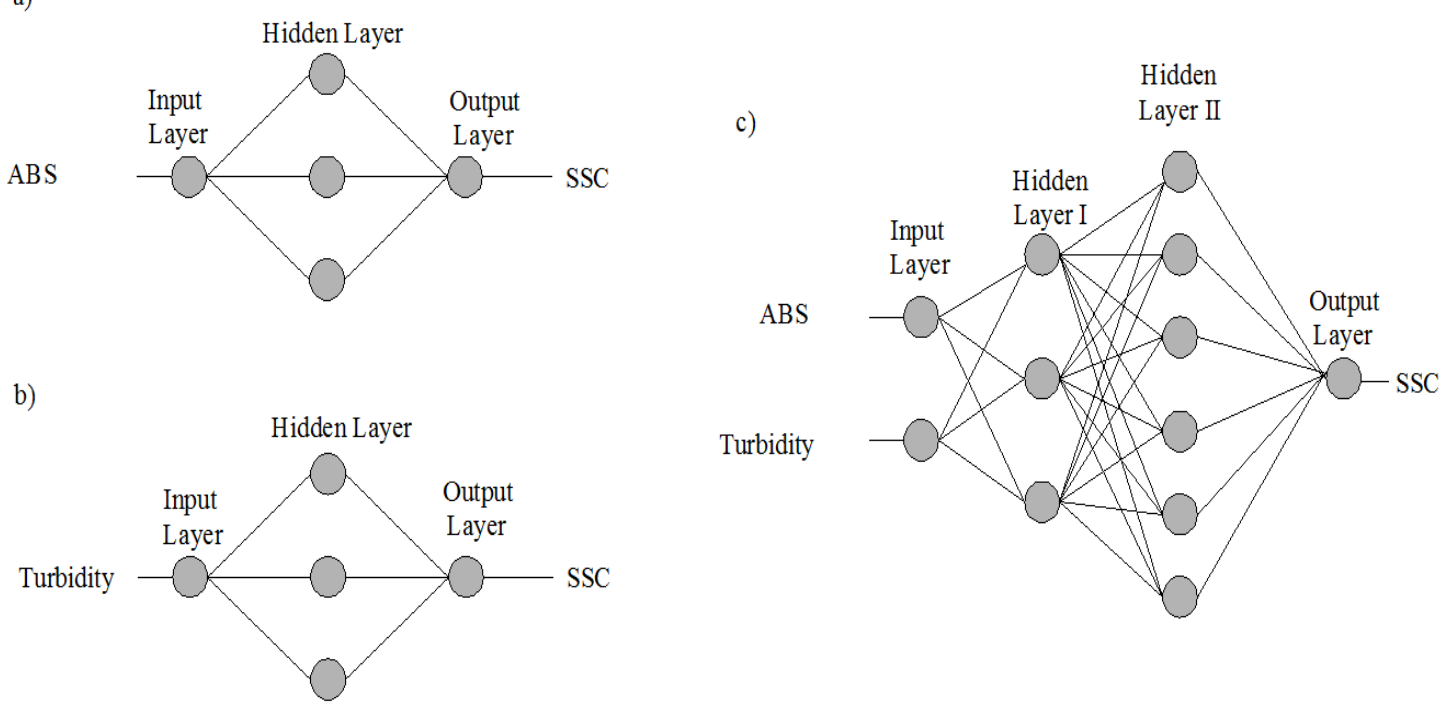

Figure 2. Structures of ANN models for sediment concentration estimation. a) Single input layer $(A B S)$. b) Single input layer (Turbidity). c) Double input layer (ABS and Turbidity)

\section{Results and discussion}

The results show that small particles had the greatest turbidity and decreasing in turbidity values depended on increases in sediment size (Fig. 3).

(a)

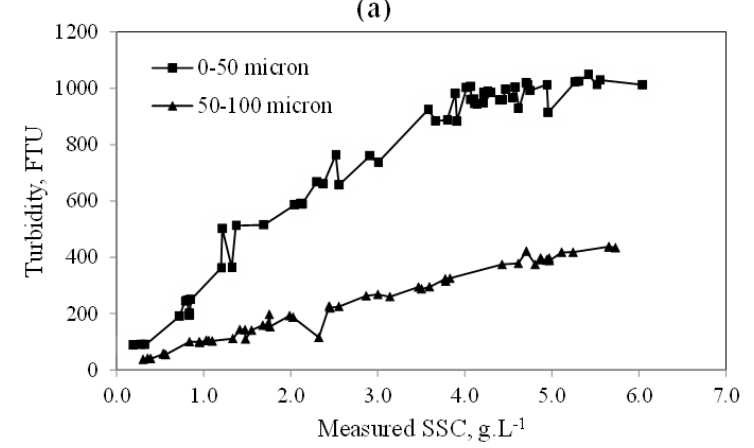

(b)

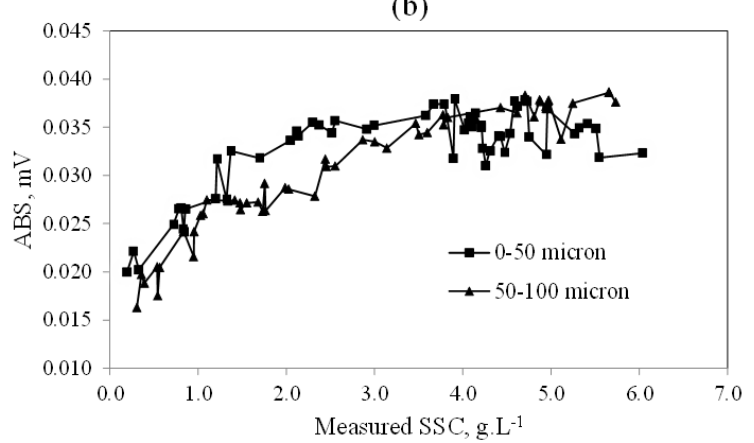

Figure 3. Observed turbidity (a) and ABS values (b) for different sediment concentrations

Similarly, Gao et al. (2008) reported that turbidity is more sensitive to fine particles than to coarse particles. This property has led to investigate the relationship between particle size distribution and turbidity. Yao et al. (2014) used different particle size and investigate its relationship with turbidity. They obtained strong correlation for bigger than 5 micron sediment size but reasonable relation was obtained only for low turbidity (0-40 NTU) under smaller sediment condition. Pavanelli and Bigi (2005) reported that a large deviation in sediment size can lead to serious errors in estimating. They prepared sediment sample groups with narrow intervals (19-31, 58-81 and 124-149 $\mu \mathrm{m})$, and 
they obtained good relationships. They concluded that sediment size problems can be eliminated with sensitive calibration but it should be consider the flow regime and water color for each river condition.

ABS measurements were observed in a large and unstable range for fine-sediment materials. Previous studies stated that clay's existence in the sediment suspension negatively effects of ABS values. This problem is essentially explained with the shape of a fine sediment (Moate and Thorne, 2009), for particle coagulation depends on the clay material, which causes unstable backscattering (Thorne and Hanes, 2002). In addition, this study's results showed that the negative effect of clay depends on the sediment concentration, especially above the level of $4.0 \mathrm{~g} \mathrm{~L}^{-1}$. This situation limits the uses of the acoustic method in certain clay-content conditions.

\section{Regression analyses}

The average FTU and ABS values for each known sediment concentration were used for regression analyses. The statistical parameters (RMSE, MAE and $\mathrm{R}^{2}$ ) values of the linear regression analysis results between sediment concentration and FTU and between sediment concentration and ABS are presented Table 1 for training and testing data. In addition estimated and measured SSC values were plotted in Figure 4 to show comparison of models for testing data.

Table 1. The statistical parameters (RMSE, MAE and $R^{2}$ ) values of the linear regression analysis results

\begin{tabular}{c|c|c|c|c|c|c|c}
\hline \multirow{2}{*}{ Inputs } & \multicolumn{3}{|c}{ Training } & \multicolumn{3}{c}{ Testing } \\
\cline { 2 - 7 } & RMSE & MAE & $\mathbf{R}^{\mathbf{2}}$ & RMSE & MAE & $\mathbf{R}^{\mathbf{2}}$ \\
\hline & \multicolumn{7}{|c}{ For smaller than $50 \mu$ m sediment group } \\
\hline ABS & 1.338 & 1.107 & 0.311 & 1.480 & 1.253 & 0.274 \\
FTU & 0.467 & 0.365 & 0.934 & 0.428 & 0.370 & 0.937 \\
FTU and ABS & 0.430 & 0.326 & 0.947 & 0.491 & 0.417 & 0.918 \\
\hline ABS & 1.094 & 0.938 & 0.904 & 1.210 & 1.050 & 0.873 \\
FTU & 0.185 & 0.139 & 0.988 & 0.340 & 0.210 & 0.967 \\
FTU and ABS & 0.175 & 0.130 & 0.990 & 0.360 & 0.200 & 0.961 \\
\hline
\end{tabular}
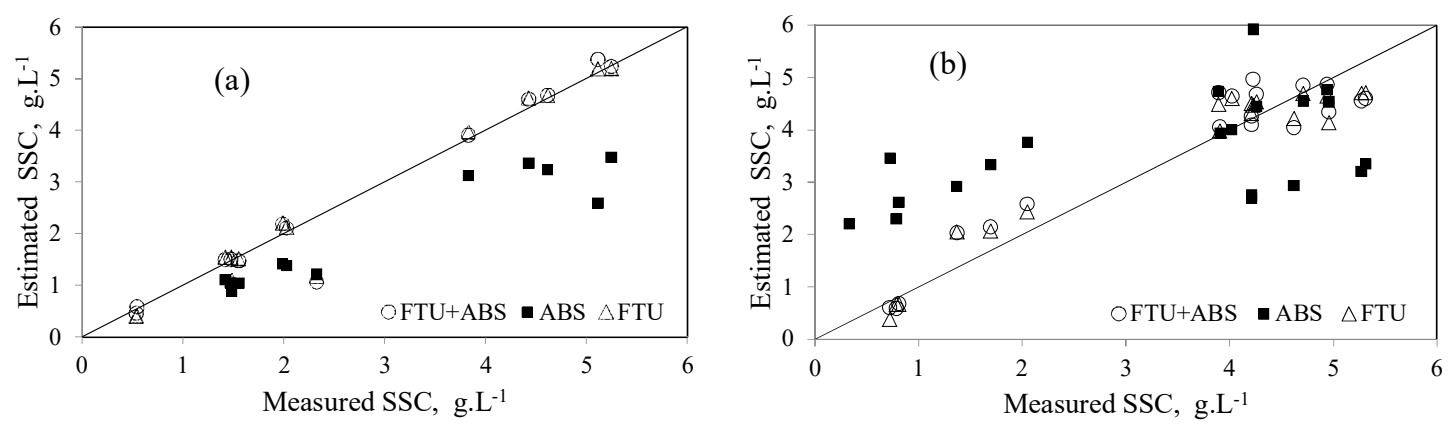

Figure 4. Regression analyses between sediment concentration (SSC) with turbidity (FTU) and acoustic backscattering signal (ABS), (a) $<50 \mu \mathrm{m}$, (b) 50-100 $\mu \mathrm{m}$ sediment group 
The turbidity values had good relationships with the SSC values $\left(\mathrm{R}^{2}=0.937\right.$ and 0.967) for testing data of each sediment groups respectively. However, the linear relationship was destroyed for values higher than 700 FTU, and this critical level was reached at the $3 \mathrm{~g} \mathrm{~L}^{-1}$ sediment concentration for the small particle size. The Seapoint Turbidity manual reported that the sensor response becomes nonlinear above 750 FTU; however, the useful range can be extended by calibrating the sensor and fitting the response to a second-order polynomial equation. Similarly, Wang et al. (2014) reported that values up to 600 FTU had good relations with SSC. It can be concluded that turbidity measurements should be conducted for lower sediment concentrations and that subsamples with dilution should be used for high concentrations (Foster et al., 1992). Due to negatively effect of small particle size, relatively lower $\mathrm{R}^{2}$ values were obtained for ABS measurements compared to turbidity values. Although ABS had a reasonable $\mathrm{R}^{2}$ value $(0.873)$ for the $50-100 \mu \mathrm{m}$ sediment group, but a significant $\mathrm{R}^{2}(0.274)$ was not produced for $<50 \mu \mathrm{m}$ sediment group. In addition, all regression equations can be used for the low-sediment concentration condition. Increasing sediment size can provide these equations for up to a $4 \mathrm{~g} \mathrm{~L}^{-1}$ concentration. Medalie et al. (2014) obtained a moderately strong relation $\left(\mathrm{R}^{2}=0.650-0.810\right)$ was found for concentrations of finegrained suspended sediments and backscatter signals up to $500 \mathrm{mg} \mathrm{L}^{-1}$ sediment concentration. However, a quite weak relationship $\left(\mathrm{R}^{2}=0.220-0.370\right)$ was observed for fine sediment for some river conditions in the same study. This problem is not related to the regression method; rather, it is a result of the problems observed in the acoustic measurement.

\section{ANN models}

The statistical parameters (RMSE, MAE and $\mathrm{R}^{2}$ ) of each ANN models were used to evaluate the alternative approaches (Tables 2 and 3 ). The reasonable $\mathrm{R}^{2}$ and RMSE results were not produced with the any ANN model that had a single ABS input for the $<50 \mu \mathrm{m}$ sediment group, and it was not considered for discussion in Table 3. This problem is caused by the negative clay particles on the ABS sediment, as mentioned above, and it was not improved with ANN models. These results show that ABS is strongly affected by sediment grain size, thus supporting the findings of previous studies. Similarly, De Falco et al. (2010) reported that backscatter signal strongly affected by sediment grain size; being directly correlated to the weight percent of the coarse fraction $(1000-1600 \mu \mathrm{m})$ and inversely correlated to weight percent of the finer sediments $(16-500 \mu \mathrm{m})$. Goff et al. (2004) did not find a significant relationship between backscatter intensity and the mean grain size of sands $(>4000 \mu \mathrm{m})$, although they found an inverse relationship with finer sediments $(0.063 \mu \mathrm{m})$. This can be explained deviation of size and distribution. Therefore, in this study; strong relationships were obtained using a single turbidity input, with the highest $R^{2}(0.970)$ for the MLP, and $\mathrm{R}^{2}(0.999)$ values in RBNN and GRNN model for testing. The use of ABS values as additional inputs (along with turbidity) did not improve the statistical parameters of this relationship. The remarkable differences were not observed among MLP, RBNN and GRNN model for this sediment size group. On the other hand, for the other sediment group $(50-100 \mu \mathrm{m})$, ABS values were used as a single input, and the highest $\mathrm{R}^{2}(0.917)$ and lowest RMSE (0.521) values were obtained for the MLP among all ANN models (Table 2). De and Chakraborty (2012) concluded that estimating the mean grain size using an acoustic inversion algorithm is computing-intensive, but this value could be estimated using an ANN-based approach in a much shorter computing 
time and with high determination coefficients ( $\mathrm{R}^{2}$ up to 0.998$)$. Similarly this study shows that single ABS input values can be used with any ANN model to estimate SSC instead of the complex acoustic algorithm. The using single turbidity for input for the 50-100 $\mu \mathrm{m}$ sediment group produces good relationships with the highest R2 (0.986) for the MLP, and $\mathrm{R}^{2}$ (0.996) values in RBNN and GRNN model for testing. In addition, for the relatively coarse sediment group, the using ABS values as an additional input with turbidity showed an improved relationship with $\mathrm{R}^{2}$ : 0.9730 .999 and 0.999 for MLP, RBNN and GRNN models respectively.

Table 2. The statistical evaluation of different ANN models for the $<50 \mu$ m sediment group

\begin{tabular}{c|c|c|c|c|c|c|c}
\hline \multirow{2}{*}{ Inputs } & \multirow{2}{*}{ Model } & \multicolumn{3}{|c|}{ Training } & \multicolumn{3}{c}{ Testing } \\
\cline { 3 - 8 } & & RMSE & MAE & $\mathbf{R}^{\mathbf{2}}$ & RMSE & MAE & $\mathbf{R}^{\mathbf{2}}$ \\
\hline FTU & MLP & 0.209 & 0.151 & 0.983 & 0.397 & 0.296 & 0.970 \\
FTU and ABS & MLP & 0.272 & 0.167 & 0.971 & 0.417 & 0.329 & 0.940 \\
\hline FTU & RBNN & 0.183 & 0.106 & 0.988 & 0.280 & 0.120 & 0.990 \\
FTU and ABS & RBNN & 0.187 & 0.093 & 0.987 & 0.290 & 0.160 & 0.990 \\
\hline FTU & GRNN & 0.116 & 0.042 & 0.995 & 0.250 & 0.100 & 0.990 \\
FTU and ABS & GRNN & 0.160 & 0.080 & 0.990 & 0.260 & 0.130 & 0.990 \\
\hline
\end{tabular}

Table 3. The statistical evaluation of different ANN models for the 50-100 $\mu$ m sediment group

\begin{tabular}{c|c|c|c|c|c|c|c}
\hline \multirow{2}{*}{ Inputs } & \multirow{2}{*}{ Model } & \multicolumn{3}{|c|}{ Training } & \multicolumn{3}{c}{ Testing } \\
\cline { 3 - 8 } & & RMSE & MAE & $\mathbf{R}^{\mathbf{2}}$ & RMSE & MAE & $\mathbf{R}^{\mathbf{2}}$ \\
\hline ABS & MLP & 0.286 & 0.222 & 0.972 & 0.400 & 0.187 & 0.936 \\
FTU & MLP & 0.131 & 0.102 & 0.994 & 0.278 & 0.202 & 0.986 \\
FTU and ABS & MLP & 0.142 & 0.094 & 0.993 & 0.297 & 0.170 & 0.973 \\
\hline FTU & RBNN & 0.068 & 0.032 & 0.998 & 0.110 & 0.050 & 0.996 \\
FTU and ABS & RBNN & 0.079 & 0.035 & 0.998 & 0.050 & 0.030 & 0.999 \\
\hline FTU & GRNN & 0.051 & 0.035 & 0.999 & 0.060 & 0.040 & 0.999 \\
FTU and ABS & GRNN & 0.032 & 0.023 & 0.999 & 0.370 & 0.280 & 0.953 \\
\hline
\end{tabular}

\section{Conclusions}

Many researchers have used the acoustic method for estimating sediment concentration in both laboratory and river conditions. Sound-scattering properties are known to become more complex with different particle sizes and sediment concentrations (Thorne and Hanes, 2002; Mouraenko, 2004). Although the acoustic algorithm is the basic method for evaluating ABS, many parameters - such as sediment and water properties, flow regime and acoustic device settings - are required to estimate sediment concentration, This method is quite complex, requires user expertise, and has some disadvantages (Meral et al., 2008). Comparatively, the ANN model is not complicated, and it can be a reasonable alternative for evaluating $A B S$ values, In addition, turbidity values have a strong relationship with a wide range of sediment concentrations at different particles sizes, and these turbidity values can be used as a single input parameter to estimate sediment concentration as an alternative to the 
acoustic method. This study's results show that the acoustic method has potential for instantaneous and continuous sediment concentration analysis with reasonable precision, and it can be improved upon using regression and ANN models, The ANN model is a powerful tool for input/output mapping, and it can facilitate the acoustic method by removing complex algorithms. A single input parameter (turbidity or ABS) can be used with the ANN model for all waters not containing clay, to get more accurate results, further regression and ANN model studies should be conducted with alternative particle sizes, shapes and densities and for varying water properties.

Acknowledgments. Financial support was provided by The Scientific \& Technological Research Council of Turkey (TÜBİTAK) for this study.

\section{REFERENCES}

[1] Aagaard, T. (2014): Sediment supply to beaches: cross-shore sand transport on the lower shoreface. - Journal of Geophysical Research: Earth Surface 119: 913-926.

[2] Abrahart, R. J., White, S. (2001): Modeling sediment transfer in Malawi: comparing backpropagation neural network solutions against a multiple linear regression benchmark using small data sets. - Physics and Chemistry of the Earth, Part B: Hydrology, Oceans and Atmosphere 26: 19-24.

[3] Alp, M., Cigizoglu, H. K. (2007): Suspended sediment estimation by feed forward back propagation method using hydro meteorological data. - Environmental Modelling \& Software 22: 2-13.

[4] APHA (2012): Standard Method 2130: Turbidity. - In: Rice, E. W., Baird, R. B., Eaton, A. D., Clesceri, L. S. (eds.) Standard Methods for the Examination of Water and Wastewater (22nd edition). American Public Health Association, American Water Works Association and Water Environment Federation, Washington, DC.

[5] Chanson, H., Takeuchi, M., Trevethan, M. (2008): Using turbidity and acoustic backscatter intensity as surrogate measures of suspended sediment concentration in a small subtropical estuary. - Journal of Environmental Management 88: 1406-1416.

[6] Cigizoglu, H. K. (2004): Estimation and forecasting of daily suspended sediment data by multi-layer perceptrons. - Advances in Water Resources 27: 185-195.

[7] Clay, C. S., Medwin, H. (1997): Acoustical Oceanography: Principles and applications. John Wiley \& Sons, New York.

[8] Crawford, A. M., Hay, A. E. (1993): Determining suspended sand size and concentration from multifrequency acoustic backscatter. - The Journal of the Acoustical Society of America 94: 3312-3324.

[9] De, C., Chakraborty, B. (2012): Estimation of mean grain size of seafloor sediments using neural network. - Marine Geophysical Research 33: 45-53.

[10] De Falco, G., Tonielli, R., Di Martino, G., Innangi, S., Simeone, S., Parnum, M. I. (2010): Relationships between multibeam backscatter, sediment grain size and Posidonia oceanica seagrass distribution. - Continental Shelf Research 30: 1941-1950.

[11] Foster, I. D. L., Millington, R., Grew, R. G. (1992): The Impact of Particle Size Controls on Stream Turbidity Measurement; Some Implications for Suspended Sediment Yield Estimation. - In: Bogen, J., Walling, D. E., Day, T. J. (eds.) Erosion and Sediment Monitoring Programmes in River Basins. Proceedings of the Oslo Symposium. International Association of Hydrological Sciences, Wallingford.

[12] Gao, P., Pasternack, G., Bali, K., Wallender, W. (2008): Estimating suspended sediment concentration using turbidity in an irrigation-dominated southeastern California watershed. - Journal of Irrigation and Drainage Engineering 134: 250-259. 
[13] Goff, J. A., Kraft, B. J., Mayer. L. A., Schock, S. G., Sommerfield, C. K., Olson, H. C., Gulick, S. P. S., Nordfjord, S. (2004): Seabed characterization on the NewJersey middle and outer shelf: correlatability and spatial variability of sea floor sediment properties. Marine Geology 209: 147-172.

[14] Gray, J. R., Glysson, G. D., Mueller, D. S. (2002): Comparability and accuracy of fluvialsediment data-a view from the US Geological Survey. - Proceedings of the American Society of Civil Engineers Hydraulics Measurements \& Experimental Methods Symposium, Estes Park, CO, July 28-August 1.

[15] Guerrero, M., Rüther, N., Szupiany, R., Haun, S., Baranya, S., Latosinski, F. (2016): The acoustic properties of suspended sediment in large rivers: consequences on ADCP methods applicability. - Water 8: 13.

[16] Hay, A. E, Sheng, J. (1992): Vertical profiles of suspended sand concentration and size from multifrequency acoustic backscatter. - Journal of Geophysical Research: Oceans 97: 15661-15677.

[17] Kisi, O. (2005): Suspended sediment estimation using neuro-fuzzy and neural network approaches. - Hydrological Sciences Journal 50(4): 683-696.

[18] Lewis, J., Eads, R, (2001): Turbidity threshold sampling for suspended sediment load estimation. - Proceedings of the 7th Federal Interagency Sedimentation Conference 25-29 March 2001, Reno, NV, USA, pp. 110-117.

[19] Maanen, B., Coco, G., Bryan, K. R., Ruessink, B. G (2010): The use of artificial neural networks to analyze and predict alongshore sediment transport. - Nonlinear Processes in Geophysics 17: 395-404.

[20] Medalie, L., Chalmers, A. T., Kiah, R. G., Copans, B. (2014): Use of Acoustic Backscatter to Estimate Continuous Suspended Sediment and Phosphorus Concentrations in the Barton River. Northern Vermont, 2010-2013. - U.S. Geological Survey, Reston, Virginia.

[21] Melesse, A. M., Ahmad, S., McClain, M. E., Wang, X., Lim, Y. H. (2011): Suspended sediment load prediction of river systems: An artificial neural network approach. Agricultural Water Management 98: 855-866.

[22] Meral, R., Thorne, P. D., Smerdon, A. M., Doğan, E. (2008): Continuous monitoring of suspended sediment in rivers by use of new methods. - International Meeting on Soil Fertility Land Management and Agroclimatology, 29 October - 1 November 2008. Kusadas1, Turkey, pp. 1007-1014.

[23] Mitchell, S. B., Lawler, D. M., West, J. R., Couperthwaite, J. S. (2003): Use of continuous turbidity sensor in the prediction of fine sediment transport in the turbidity maximum of the trent Estuary UK. - Estuarine, Coastal and Shelf Science 58: 645-652.

[24] Moate, B. D., Thorne, P. D. (2009): Measurements and inversion of acoustic scattering from suspensions having broad size distributions. - The Journal of the Acoustical Society of America 126: 2905-2917.

[25] Mouraenko, O. A. (2004): Acoustic measurement techniques for suspended sediments and bedforms. - Ph. D. Dissertation, University of Florida, pp. 7-34.

[26] Nagy, H. M., Watanabe, K., Hirano, M. (2002): Prediction of sediment load concentration in rivers using artificial neural network model. - Journal of Hydraulic Engineering 128: 588-595.

[27] Neubauer, W. G., Vogt, R. H., Dragonette, L. R. (1974): Acoustic reflection from elastic spheres. I. Steady-state signals. - The Journal of the Acoustical Society of America 55: 1123-1129.

[28] Nourani, V. N., Kalantari, O. (2010): Integrated artificial neural network for spatiotemporal modeling of rainfall-runoff-sediment processes. - Environmental Engineering Science 27: 411-422.

[29] O'Hara Murray, R. B., Hodgson, D. M., Thorne, P. D. (2012): Wave groups and sediment resuspension processes over evolving sandy bedforms. - Continental Shelf Research 46: 16-30. 
[30] Pavanelli, D., Bigi, A. (2005): Indirect methods to estimate suspended sediment concentration: reliability and relationship of turbidity and settleable solids. - Biosystems Engineering 9: 75-83.

[31] Pedocchi, F., Garcia, M. H. (2012): Acoustic measurement of suspended sediment concentration profiles in an oscillatory boundary layer. - Continental Shelf Research 46: 87-95.

[32] Ruessink, B. G., Michallet, H., Abreu, T., Sancho, F., Van der Werf, J., Silva, P. (2011): Observations of velocities, sand concentrations, and fluxes under velocity-asymmetric oscillatory flows. - Journal of Geophysical Research: Oceans 116 (C3): C03004.

[33] Schaafsma, A. S., Hay, A. E (1997): Attenuation in suspensions of irregularly shaped sediment particles: a two-parameter equivalent spherical scatterer model. - The Journal of the Acoustical Society of America 102: 1485-1502.

[34] Schoellhamer, D. H., Wright, S. A. (2003): Continuous Monitoring of Suspended Sediment Discharge in Rivers by Use of Optical Backscatterance Sensors. - In: Bogen, J., Fergus, T., Walling, D. E. (eds.) Erosion and Sediment Transport Measurement: Technological and Methodological Advances. International Association of Hydrological Sciences, Wallingford.

[35] Sheng, J., Hay, A. E (1988): An examination of the spherical scatterer approximation in aqueous suspensions of sand. - The Journal of the Acoustical Society of America 83: 598-610.

[36] Singha, A., Imtiyaz, M., Isaacc, R. K., Denis, D. M. (2012): Comparison of soil and water assessment tool (SWAT) and multilayer perceptron (MLP) artificial neural network for predicting sediment yield in the Nagwa agricultural watershed in Jharkhand, India. Agricultural Water Management 104: 113-120.

[37] Slaets, J. I, Schmitter, P., Hilger, T., Lamers, M., Piepho, H. P., Vien, T. D. A. (2014): Turbidity-based method to con-tinuously monitor sediment, carbon and nitrogen flows inmountainous watersheds. - Journal of Hydrology 513: 45-57.

[38] Smerdon, A. M (2006): AQUAscat; ABS System User Manual. - Aquatec Electronics Limited, Hartley Wintney.

[39] Sun, H., Cornish, P. S, Daniell, T. M (2001): Turbidity based erosion estimation in catchment in South Australia. - Journal of Hydrology 253: 227-238.

[40] Tananaev, N. I, Debolskiy, M. V. (2014): Turbidity observations in sediment flux studies: Examples from Russian rivers in cold environments. - Geomorphology 218: 63-71.

[41] Tfwala, S. S., Wang, Y. M. (2016): Estimating sediment discharge using sediment rating curves and artificial neural networks in the Shiwen River Taiwan. - Water 8: 53.

[42] Thorne, P. D., Hanes, D. M. (2002): A review of acoustic measurement of small-scale sediment processes. - Continental Shelf Research 22: 603-632.

[43] Thorne, P. D., Hurther, D. (2014): An overview on the use of backscattered sound for measuring suspended particle size and concentration profiles in non-cohesive inorganic sediment transport studies. - Continental Shelf Research 73: 97-118.

[44] Thorne, P. D., Meral, R. (2008): Formulations for the scattering properties of suspended sandy sediments for use in the application of acoustics to sediment transport processes. Continental Shelf Research 28:309-317.

[45] Thorne, P. D., Hardcastle, P. J., Soulsby, R. L. (1993): Analysis of acoustic measurements of suspended sediments. - Journal of Geophysical Research: Oceans 98: 899-910.

[46] Thorne, P. D., Hardcastle, P. J., Dolby, J. W (1998): Investigation into the application of cross-correlation analysis on acoustic backscattered signals from suspended sediment to measure nearbed current profile. - Continental Shelf Research 18: 695-714.

[47] Thosteson, E. D., Hanes, D. M. (1998): A simplified method for determining sediment size and concentration from multiple frequency acoustic backscatter measurements. - The Journal of the Acoustical Society of America 104: 820-830. 
[48] Uncles, R. J., Stephens, J. A. (2010): Turbidity and sediment transport in a muddy subestuary. - Estuarine, Coastal and Shelf Science 87: 213-224.

[49] Wang, A. J., Ye, X., Du, X., Zheng, B. (2014): Observations of cohesive sediment behaviors in the muddy area of the northern Taiwan Strait, China. - Continental Shelf Research 90: 60-69.

[50] Wang, Y. M., Kerh, T., Traore, S. (2009): Neural networks approaches for modelling river suspended sediment concentration due to tropical storms. - Global NEST Journal 11: 457-466.

[51] Williamson, T. N., Crawford, C. G (2011): Estimation of suspended-sediment concentration from total suspended solids and turbidity data for Kentucky, 1978-1995. JAWRA Journal of the American Water Resources Association 47: 739-749.

[52] Wilson, G. W., Hay, A. E. (2015): Acoustic backscatter inversion for suspended sediment concentration and size: A new approach using statistical inverse theory. - Continental Shelf Research 106: 130-139.

[53] Wren, D. G., Barkdoll, B. D., Kuhnle, R. A., Derrow, R. W. (2000): Field techniques for suspended sediment measurement. - Journal of Hydraulic Engineering 126: 97-104.

[54] Yao, M., Nan, J., Chen, T. (2014): Effect of particle size distribution on turbidity under various water quality levels during flocculation processes. - Desalination 354:116-124.

[55] Yitian, L., Gu, R. R. (2003): Modeling flow and sediment transport in a river system using an artificial neural network. - Environmental Management 31: 122-134.

[56] Ziegler, C. A. (2002): Issues related to use of turbidity measurements surrogate for suspended sediment. - Turbidity and Other Sediment Surrogates Workshop, April 30May 2, 2002, Reno, NV. 